\title{
Influence of Vegetation Cover on the Oh Soil Moisture Retrieval Model: A Case Study of the Malinda Wetland, Tanzania
}

\author{
Fridah Kirimi ${ }^{1}$, David N. Kuria ${ }^{2}$, Frank Thonfeld ${ }^{1}$, Esther Amler ${ }^{1}$, Kenneth Mubea ${ }^{2}$, \\ Salome Misana ${ }^{3}$, Gunter Menz ${ }^{1}$ \\ ${ }^{1}$ Department of Geography, University of Bonn, Bonn, Germany \\ ${ }^{2}$ Institute of Geomatics, GIS \& Remote Sensing, Dedan Kimathi University of Technology, Nyeri, Kenya \\ ${ }^{3}$ Department of Geography, University of Dar es Salaam, Dar es Salaam, Tanzania \\ Email: *f.kirimi@geographie.uni-bonn.de
}

Received 1 December 2015; accepted 4 March 2016; published 7 March 2016

Copyright (C) 2016 by authors and Scientific Research Publishing Inc.

This work is licensed under the Creative Commons Attribution International License (CC BY).

http://creativecommons.org/licenses/by/4.0/

c) (7) Open Access

\section{Abstract}

Soil moisture is an important parameter that drives agriculture, climate and hydrological systems. In addition, retrieval of soil moisture is important in the analysis as well as its influence on these systems. Radar imagery is best suited for this retrieval due to its all-weather capability and independence from solar irradiation. Soil moisture retrieval was done for the Malinda Wetland, Tanzania, during two time periods, March and September 2013. The aim of this paper was to analyze soil moisture retrieval performance when vegetation contribution is taken into account. Backscatter values were obtained from TerraSAR-X Spotlight mode imagery taken in March and September 2013. The backscatter values recorded by SAR imagery are influenced by vegetation, soil roughness and soil moisture. Thus, in order to obtain the backscatter due to soil moisture, the roughness and vegetation contribution are determined and decoupled from total backscatter. The roughness parameters were obtained from a Digital Surface Model (DSM) from Unmanned Aerial Vehicle (UAV) photographs whereas the vegetation parameter was obtained by inverting the Water Cloud Model (WCM). Lastly, soil moisture was retrieved using the $\mathrm{Oh}$ Model. The coefficient of correlation between the observed and retrieved was 0.39 for the month of March and 0.65 in the month of August. When the vegetation contribution was considered, the $r^{2}$ for March was 0.64 and that in August was 0.74. The results revealed that accounting for vegetation improved soil moisture retrieval.

\section{Keywords}

Surface Soil Moisture, Oh Model, Water Cloud Model, Wetland, TerraSAR-X

\footnotetext{
${ }^{*}$ Corresponding author.
}

How to cite this paper: Kirimi, F., Kuria, D.N., Thonfeld, F., Amler, E., Mubea, K., Misana, S. and Menz, G. (2016) Influence of Vegetation Cover on the Oh Soil Moisture Retrieval Model: A Case Study of the Malinda Wetland, Tanzania. Advances in Remote Sensing, 5, 28-42. http://dx.doi.org/10.4236/ars.2016.51003 


\section{Introduction}

Wetlands perform various ecological, economic and cultural functions with provision of water for agricultural activities being fundamental. However, with the increase in global population, there is growing need for increased food production. Consequently, this translates to habitation of the wetlands with increased influx occurring in the dry season when there is low water availability [1]. Soil moisture content has been reported as being an important variable with respect to influencing climate change dynamics and other hydrological applications [2] [3]. While soil moisture can be observed at single point using gravimetric or Time Domain Reflectometry (TDR) probing, it is difficult to cover wide areas with this method. Thus, this necessitates the use of satellite remote sensing, particularly in the microwave region of the electromagnetic spectrum [4] [5]. Passive Microwave remote sensing produces coarse spatial resolution imagery, whose soil moisture retrievals can further be improved by combining passive and active products [6] [7]. Active Microwave Remote Sensing (AMRS) utilize Synthetic Aperture Radar (SAR) which is capable to provide high spatial resolution and can be used to derive soil moisture under bare ground conditions as well as vegetated regions. In vegetated landscapes, the contribution of backscatter from vegetation has to be determined before the soil moisture is derived. The wave interaction and response with targets differs depending on the portion of the electromagnetic spectrum utilized. The penetration depth of the wave mainly depends on the frequency of the radiation and the conditions of the target. The longer wavelength P-band (250 - 500 MHz) is able to penetrate further into soil as opposed to shorter L (0.5 - $1.5 \mathrm{GHz}$ ) and X (8 - $12 \mathrm{GHz}$ ) bands. Depending on the density of vegetation cover and vertical structure, penetration through the vegetation canopy also differs. In dense vegetation, longer wavelength $\mathrm{P}$ band can sense stem structure and soil surface, while L-Band waves penetrate to some depth in canopy and are capable of sensing branches and part of the stem. The signals from soil surface are attenuated completely. In densely vegetated areas however, X-Band waves bounce off vegetation canopy and backscatter signals do not include contribution from soil surface. Figure 1 illustrates the concept of penetration of microwave radiation for a vegetated target.

Total backscatter is measured in decibels $(\mathrm{dB})$ and is a function of vegetation, soil roughness and soil moisture [8]-[10] as shown in Equation (1)

$$
\sigma_{\text {total }}^{0}(\mathrm{~dB})=f(\text { vegetation, soil_roughness, soil_moisture })
$$

where $\sigma_{\text {total }}^{0}$ is the calibrated total backscatter.

Sensitivity of radar backscattering to soil moisture and roughness has been demonstrated in different papers [5] [11] [12] considering the variation in dielectric constant of wet ( $~ 80)$ and dry ( 6) soils. Challenges in discriminating the contribution from soil moisture and roughness [13] still remain. The presence of vegetation further complicates soil moisture retrieval [14]. Several approaches are in use for soil moisture retrieval including use of models such as theoretical, semi empirical and empirical methods [15]-[19]. Theoretical models are based on theoretical interactions between backscatter, soil moisture and roughness. Empirical methods are

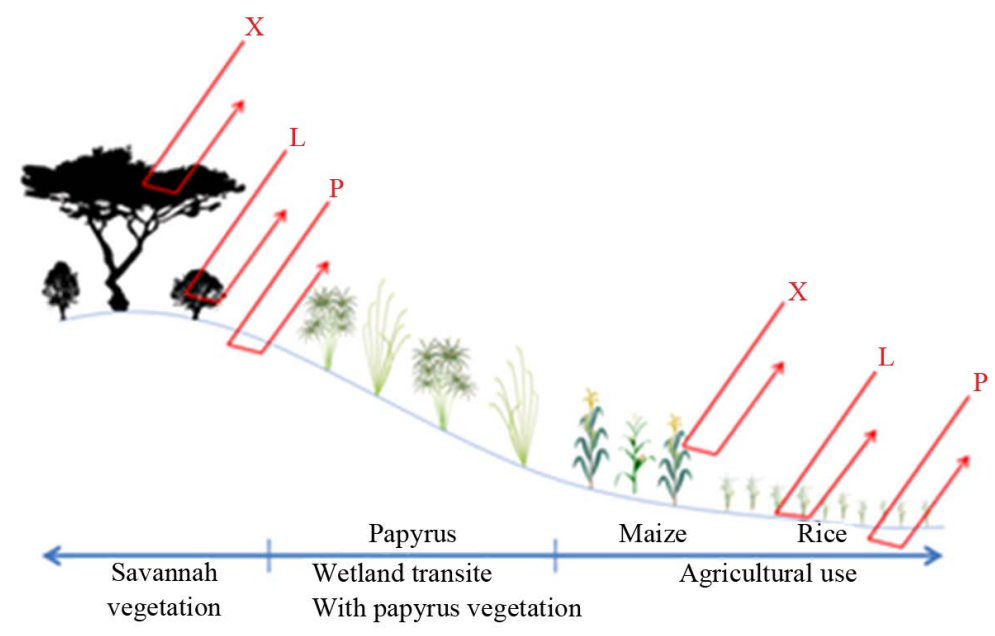

Figure 1. Schematic illustration of interaction of different P, L, X radar electromagnetic waves with different types of vegetated targets. 
based on experiments with large collections of datasets while semi empirical models are based on a combination of theory and experimental datasets. Semi empirical models include the Oh Model [20], Dubois [21] and Water Cloud Model (WCM) [22].

The Water Cloud Model [22] considers the vegetation canopy as a cloud of water droplets that have randomly been distributed in the canopy. The Water Cloud Model has been proven highly useful in the determination of vegetation parameters. It has been utilized to determine the vegetation contribution by using Leaf Area Index (LAI), vegetation water content and biomass as the canopy descriptors [9] [23]-[25].

When exploiting TerraSAR-X imagery for soil moisture retrieval, studies have shown the contribution of vegetation backscatter to overall backscatter. [26] showed that $X$ band is sensitive to density and size of canopy elements while [27] opted to derive soil moisture in areas with the Normalized Difference Vegetation Index (NDVI) less than 0.25, indicative of bare soils. In another study by [28], X-band was found to better discriminate bare and vegetated fields. This emphasizes the importance of incorporating vegetation contribution when determining the soil moisture from X-band imagery. Vegetation vigor can also be extracted from Unmanned Aerial Vehicle (UAV) photography. [29] extracted NDVI, Green Normalized Difference Vegetation Index and Soil Adjusted Vegetation Index showing application of UAV derived vegetation indices for agriculture. In addition to the indices used by [29] [30] derived the Green Ratio Vegetation Index and Green Soil Adjusted Vegetation Index from UAV to monitor crops.

In this paper, dual season TerraSAR-X images were utilized in the retrieval of information about seasonality of soil moisture. The objectives of the study were to assess the impact of vegetation as an additional parameter in soil moisture retrieval. Utilization of the Red Green Vegetation Index (RGVI) is evaluated as a canopy descriptor in soil moisture retrieval more so when the NIR band is not available. UAV photographs taken in the visual spectrum of the electromagnetic spectrum are used. Additionally, the use of a combination of soil moisture retrieval models was assessed. In Section 2, the study area, methodology and data processing are described. In Section 3 results are presented and in Section 4, the summary and conclusions are presented.

\section{Study Area and Data}

\subsection{Study Area}

Malinda wetland is within the Pangani flood plain in the Korogwe District of Tanga, Tanzania. It lies between latitudes $5^{\circ} 04^{\prime} 22.8^{\prime \prime} \mathrm{S}-5^{\circ} 05^{\prime} 52.8^{\prime \prime} \mathrm{S}$ and longitudes $38^{\circ} 19^{\prime} 04.8^{\prime \prime} \mathrm{E}-38^{\circ} 20^{\prime} 38.4^{\prime \prime} \mathrm{E}$ and has a size of 354.6 hectares (Figure 2). River Mkomazi, a tributary of Pangani (Ruvuma) River forms the lower boundary of the wetland. To the north of the wetland lie the Usambara Mountains. The region experiences bimodal rainfall with long rains experienced in March-May and short rains from September-November. During the image acquisition period in March it was dry, just before the rainy season started, and in September the area was still moist with the crops reaching maturity. The main economic activity of the surrounding area is rain-fed agriculture with so far little irrigated agriculture on the wetland's periphery. The dominant crop is maize.

\subsection{Data}

The data used included ground measurements, satellite imagery and UAV photos (Table 1). Two TerraSAR-X images were acquired on $28^{\text {th }}$ March 2013 and $9^{\text {th }}$ September 2013 from DLR (German Aerospace Centre). The field data consisted of soil moisture measurements at a depth of $5 \mathrm{~cm}$ using TDR probes. Data was collected from $5^{\text {th }}$ to $8^{\text {th }}$ March 2013 just before the rainy season and $19^{\text {th }}$ to $23^{\text {rd }}$ August 2013 during which time the fields had mature maize approaching harvesting. A Digital Surface Model (DSM) was generated from UAV photos, which was later used to generate the roughness parameters required as inputs in the retrieval algorithm.

The precipitation data corresponding to the satellite imagery collection dates are as shown in Figure 3.

\subsection{Methods}

Figure 4 illustrates the soil moisture retrieval work flow. Field work was organized in two parts which were executed in similar fashion. The first part was carried out from $5^{\text {th }}$ to $8^{\text {th }}$ March 2013 while the second part was carried out from $19^{\text {th }}$ to $23^{\text {rd }}$ August 2013. The field work planning involved liaison with support colleagues in Korogwe on the best periods to have observations and pursuing permissions to visit and undertake the data collection. 


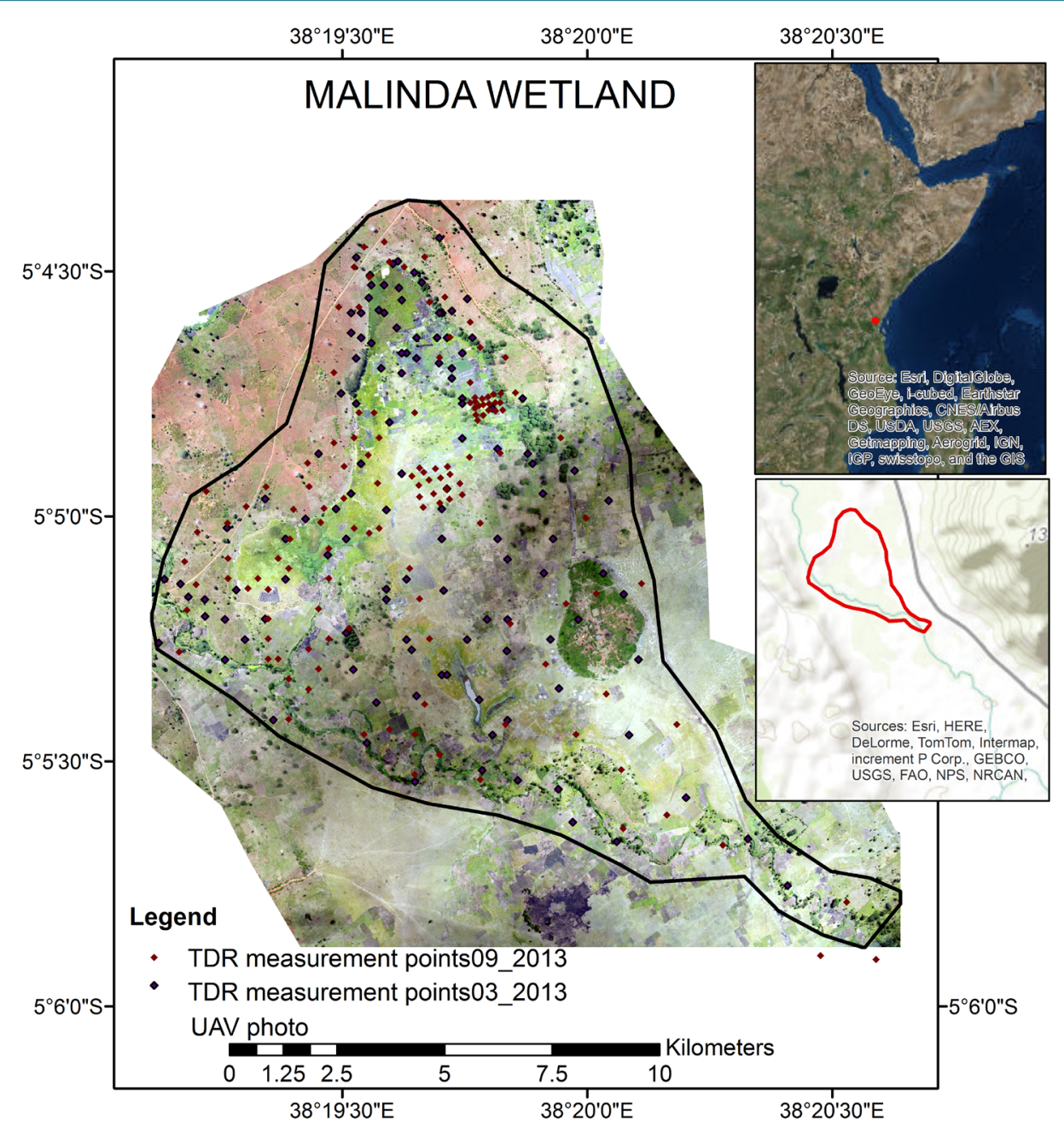

Figure 2. The Malinda Wetland study area within the Pangani flood plain in Northern Tanzania.

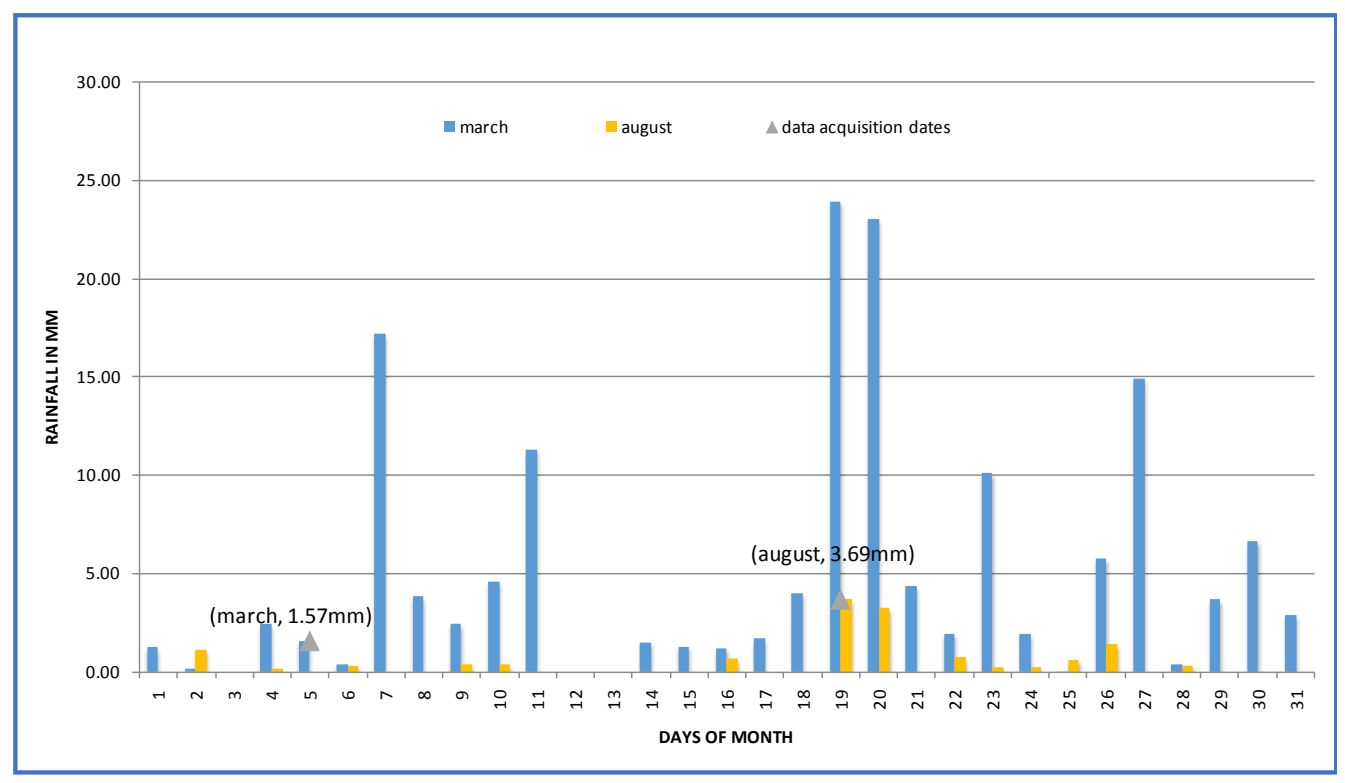

Figure 3. Malinda Rainfall in March and August 2013. 


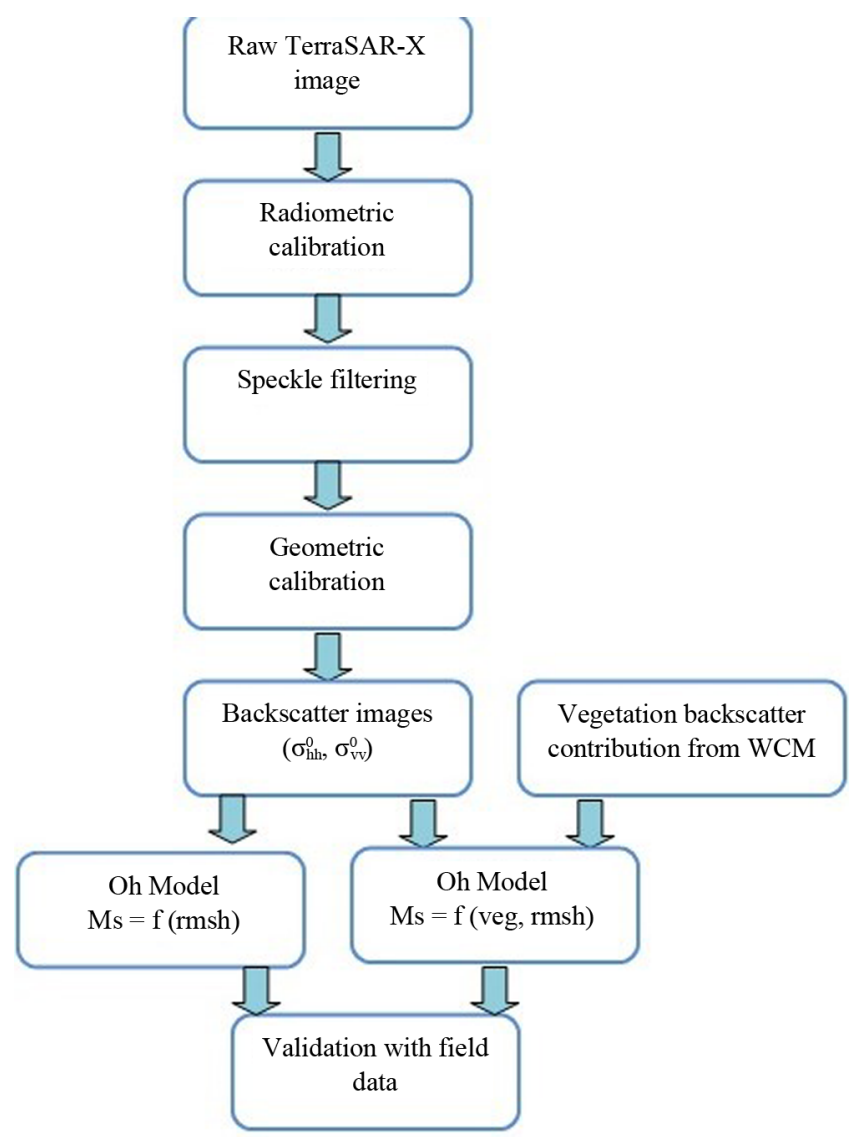

Figure 4. Soil moisture retrieval workflow (for the explanation of abbreviations see text).

Table 1. Datasets used in this study.

\begin{tabular}{ccc}
\hline Dataset & Source & Period \\
\hline Soil moisture (169 points) & Field Survey & $5^{\text {th }}-8^{\text {th }}$ March 2013 \\
Soil moisture (158 points) & Field Survey & $19^{\text {th }}-23^{\text {rd }}$ August 2013 \\
TerraSAR-X & DLR & $28^{\text {th }}$ March 2013 \\
TerraSAR-X & DLR & $9^{\text {th }}$ September 2013 \\
Aerial Ortho Photos & UAV & May and August 2012 \\
DSM & UAV photos post processing & May and August 2012 \\
\hline
\end{tabular}

The field work step involved actual site visits during which TDR probes were used to pick soil moisture data. The points at which the moisture was picked were also located using DGPS. This was necessary for locating these points and correlating them precisely with the corresponding satellite data.

The interpolation step involved analysis of the soil moisture data collected and its interpolation to a distributed format. Various interpolation schemes exist but for this work we have used Kriging approaches since they are reported as providing spatially consistent estimations [31].

The soil moisture retrieval step comprised of the Oh model using the backscatter values as input and site specific soil parameters i.e. root mean square height (rmsh) and correlation length $(\ell)$. The DSM from UAVs was used to generate surface roughness parameters, namely the rmsh and correlation length $(\ell)$. Soil moisture is first retrieved using the Oh model which does not take into account vegetation effect. The vegetation aspect is defined using the semi empirical WCM using indices from the red and green bands from UAV flight photographs. The Oh model was then used to retrieve soil moisture with resulting vegetation effect free backscatter. The 
effect of incorporating the vegetation contribution in soil moisture retrieval is analyzed in such a case when the NIR band is not available. Using the WCM, vegetation indices were used to derive the vegetation water content. This aided in decoupling the backscatter contribution from vegetation and that from soil. A vegetation water content map and a soil moisture map were then derived.

\subsection{Terra SAR X processing}

TerraSAR-X data is presented as 16-bit Digital Numbers (DNs) in two polarizations (HH and VV) at spatial resolution of $1 \mathrm{~m}$ (spotlight mode). For the retrieval of soil moisture, DNs were converted to Sigma Nought $\left(\sigma_{0}\right)$. The formulation for this conversion is provided in the technical documentation of DLR [32]. The equations for deriving backscatter from TerraSar $\mathrm{X}$ are indicated in Equation (2).

$$
\begin{aligned}
& \beta^{0}=k_{f}|D N|^{2} \\
& \sigma^{0}=\beta^{0} \sin \theta_{l o c}-\mathrm{NESZ} \\
& \mathrm{NESZ}=\mathrm{NEBN} \sin \theta_{l o c} \\
& \mathrm{NEBN}=k_{f} \sum_{i-0}^{\operatorname{deg}} \operatorname{coeff}\left(\tau-\tau_{r e f}\right)^{i}, \tau \in \llbracket \tau_{\min }, \tau_{\max } \rrbracket \\
& \beta^{0} \text { is_radarbrightness, } k_{f} \text { is_calibration_factor, } \\
& \sigma^{0} \text { is_sigma_naught, } \theta_{l o c} \text { is_the_local_incidence_angle, } \\
& \text { NESZ_is_Noise_Equivalent_Sigma_Zero, } \\
& \text { NEBN_is_Noise_Equivalent_Beta_Naught }
\end{aligned}
$$

The NEBN coefficients are obtained from the XML configuration file that is delivered with the datasets. The local incidence angle determines the backscatter received by the sensor. This is computed by considering look angles at every pixel and corresponding slope. The decision on whether incidence angle of radar increase or decrease depends on the aspect at each pixel. The equation for computing the Radar Incidence Angle is shown in Equation (3).

$$
\theta_{\text {radar }}=\beta^{0}-(\text { aspect } \times \text { slope })
$$

\subsection{Surface Roughness Data}

To support the retrieval of soil moisture, a number of preparatory steps were undertaken. The first addresses the surface roughness parameterization. The roughness parameters were computed from the DSM using a moving window of 16 pixels. The rmsh describes the vertical component and the correlation length describes the horizontal component of roughness.

$$
\begin{gathered}
r m s h=\sqrt{\frac{\sum_{i=1}^{n}\left(Z_{i}-\bar{Z}\right)^{2}}{n-1}} \\
p\left(x^{\prime}\right)=\frac{\sum_{(i=1)}^{(N+1-j)} Z_{i} Z_{(j+i-1)}}{\sum_{(i=1)}^{N} Z_{i}^{2}}
\end{gathered}
$$

$Z_{i}$ is the vertical height at location $i, \bar{Z}$ is the mean vertical height of the soil surface for $\mathrm{n}$ samples. The Auto Correlation Function (ACF) describes the degree of correlation between the height $Z_{i}$ at location $i$ and the height $Z_{i+j}$ at a horizontal distance $x$ from $i$ [33]-[36].

The correlation length is the horizontal distance at which the $\mathrm{p}(\mathrm{l})$ drops below (1/e) where e is the Euler's number. 


\subsection{Soil Moisture Ground Truth Data}

Soil moisture observations were carried out at $5 \mathrm{~cm}$ depths using calibrated TDR probes between $5^{\text {th }}$ and $8^{\text {th }}$ March 2013 while during the second field campaign observations were done between $19^{\text {th }}$ and $23^{\text {rd }}$ August 2013. During the March campaign, a total number of 169 sampling points were distributed throughout the Malinda wetland. In the August campaign 158 sampling points were collected.

The voltage sensed, location coordinates and land use/cover at the time of observation was recorded. The voltage collected was converted to equivalent moisture using Equation (6) provided in the TDR probe user manual.

$$
m_{s}=\frac{\left(1.07+6.4 V-6.4 V^{2}+4.7 V^{3}-a_{0}\right)}{a_{1}}
$$

$$
\begin{aligned}
& m_{s-} \text { is_soilmoisture, } V \text { _is_voltage, } \\
& a_{0}, a_{1} \text { _are_coefficients_related_to_wetland_soil_types }
\end{aligned}
$$

Corresponding TerraSAR-X data were ordered for $28^{\text {th }}$ March 2013 and $9^{\text {th }}$ September 2013. In both instances there were challenges in having the concurrent field measurement and satellite over-passes. To obtain the spatially distributed soil moisture, interpolation techniques were employed.

\subsection{Vegetation Moisture Data}

Wetlands typically have vegetation cover most of the times; there is therefore need to model the vegetation contribution to the sensed backscatter. There are several approaches which can be used (Figure 5). These include the semi-empirical Water Cloud Model (WCM) [22], Radiative Transfer Model (RTM) [37] and 3D parameterizations [38]. In this work the (WCM) was used. In WCM, the vegetation contribution is incorporated into the soil moisture retrieval algorithm.

The WCM is setup as follows:

$$
\begin{aligned}
& \sigma^{0}=\sigma_{v e g}^{0}+\tau^{2} \sigma_{\text {soil }}^{0} \\
& \sigma_{\text {veg }}^{0}=A^{*} m_{v} * \cos \theta\left(1-\tau^{2}\right) \\
& \tau^{2}(\text { two_way_vegetation_transmissivity })=\mathrm{e}^{\left(-2^{*} B^{*} m_{v}{ }^{*} \sec \theta\right)} \\
& m_{v \_} \text {is_vegetation_water_content, } \\
& \text { A_and_B_are_parameters_dependent_on_vegetation_type, } \\
& \theta \text { is_the_incidence_angle } \\
& A=0.0012, B=0.091
\end{aligned}
$$

Equation (7) shows the Water Cloud Model. A and B are determined from field experiments for generalized land uses [39]. Auxiliary information such as NDVI, LAI and fraction cover would suffice in defining the vegetation contribution of backscatter. None of the above parameters were available for this study, thus the RGVI was used in this research to decouple the contribution from vegetation and soil. UAV photos were used to obtain this surrogate vegetation index [1]. Equation 8 shows the

Red Green Vegetation Index $($ rgvi $)=($ red - green $) /($ red + green $)$

Substituting the parameters leads to the modified WCM equation:

$$
\begin{aligned}
& \sigma_{\text {veg }}^{0}=A^{*} m_{v} * \cos \theta\left(1-\mathrm{e}^{\left(-2^{*} B^{*} m_{v} * \sec \theta\right)}\right) \\
& \sigma_{\text {veg }}^{0}=0.0012 * r g v i * \cos \theta\left(1-\mathrm{e}^{\left(-2^{*} 0.091 * r g v i * \sec \theta\right)}\right)
\end{aligned}
$$

\subsection{Soil Moisture Retrieval}

There are various models used in soil moisture retrieval which have been postulated in literature. The Oh Model 


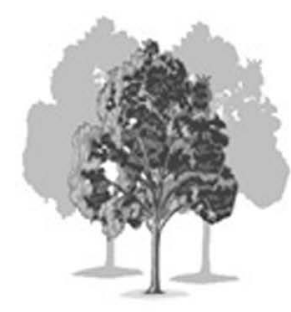

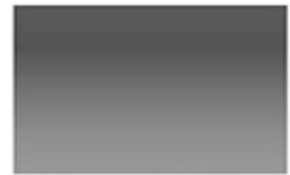

Attema and Ulaby (1978)

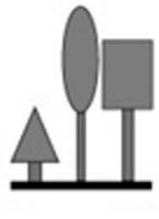

Karam et al. (1992)

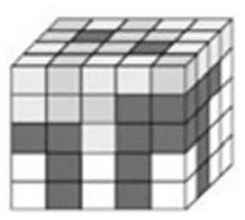

Ewe and Chuah (2000)

Level of complexity and underst anding

Figure 5. Vegetation models showing vegetation cover, Water Cloud Model (WCM), Radiative Transfer Model (RTM) and 3D parameterization.

was used in this research and was tested using a diverse array of soil types and hydrological conditions. The model uses co- and cross-polarization ratios of backscatter coefficients to estimate the soil moisture (Equation 9).

$$
\begin{aligned}
& p=\frac{\sigma_{h h}^{0}}{\sigma_{v v}^{0}}=1-\left(\frac{\theta}{90^{\circ}}\right)^{\left(0.35^{*} m_{s}^{*}(-0.65)\right)} * \mathrm{e}^{-0.4(k s)^{1.4}} \\
& q=\frac{\sigma_{h v}^{0}}{\sigma_{v v}^{0}}=0.1\left(\frac{s}{l}+\sin 1.3 \theta\right)^{1.2} *\left(1-\mathrm{e}^{-0.9(k s)^{0.8}}\right) \\
& \sigma_{h v}^{0}=0.11 m_{s}^{0.7}(\cos \theta)^{2.2} *\left(1-\mathrm{e}^{-0.32(k s)^{1.8}}\right)
\end{aligned}
$$

The soil moisture was retrieved from the above equations in two cases. Case I did not consider the vegetation contribution in the retrieval. Case II eliminated the effect of vegetation using the $\sigma_{\text {veg }}^{0}$ computed from WCM. Hence, the backscatter used as input in the Oh model was a function of roughness and soil moisture as shown in Equation (10).

$$
\sigma_{(\text {roughness,moisture) }}^{0}=\frac{f(\text { vegetation, soil_roughnesss, soil_moisture })}{f(\text { vegetation })}
$$

\section{Results and Discussion}

\subsection{Ground Truth TDR Soil Moisture Distribution}

Figure 6 shows the soil moisture distribution for March and September 2013. The soil moisture range was between 2.5\% - 30\% volume in March 2013. In September 2013, it ranged from 16\% - 60\% volume. The September image is wetter due to the rains experienced prior to the soil moisture data collection.

\subsection{Oh Soil Moisture Retrieval}

The rmsh for surface roughness obtained from the DSM is shown in Figure 7. The rmsh from the UAV photos ranged from 0.024 to $0.381 \mathrm{~cm}$. This falls in the random roughness class [36] indicative of soil aggregates and clods. Except for very few areas, the roughness was consistent in most of the study area.

Figure 8 shows case I retrievals of soil moisture taking no account of vegetation cover. The dots represent observed soil moisture and the sizes of the dots are indicative of the magnitude of soil moisture in the different locations within the study area. From these retrievals there are some correspondences with the observed distribution, though regions with low vegetation cover exhibit better correspondence.

The wetland has substantial vegetation at any given time and this coupled with the short wave sensor used explains in part the reason for the retrievals. The assumption was that there was no presence of vegetation, but the actual situation is compounded by the presence of medium-to-low vegetation cover, mainly rice and maize.

The retrievals for March are generally overestimating the soil moisture conditions, while those of September are underestimating. In March, the region is dry and thus backscatter contribution is increased by attenuation of low vegetation cover as this is the period just before the onset of the April rains. During the wetter season in 
TDR SOIL MOISTURE INTERPOLATION_3_13

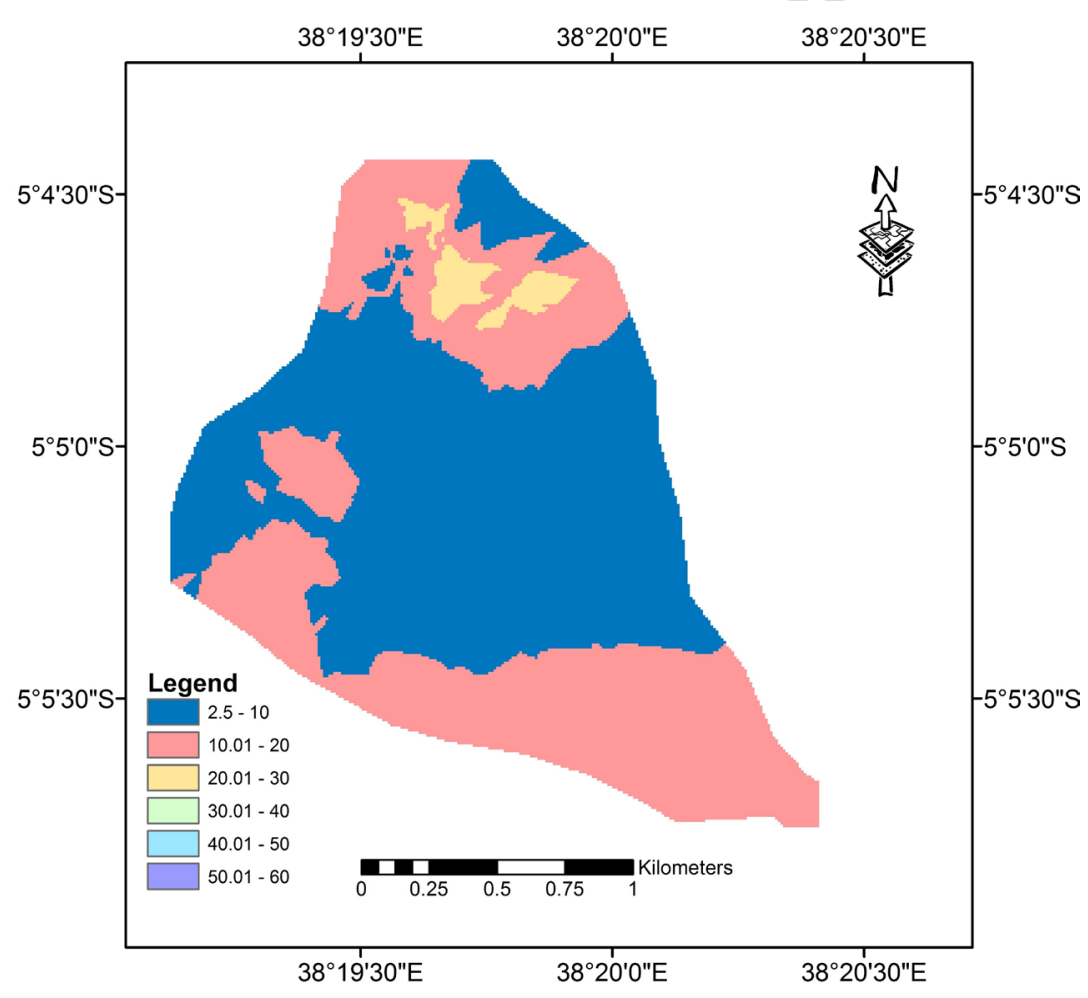

(a)

TDR SOIL MOISTURE INTERPOLATION_9_13

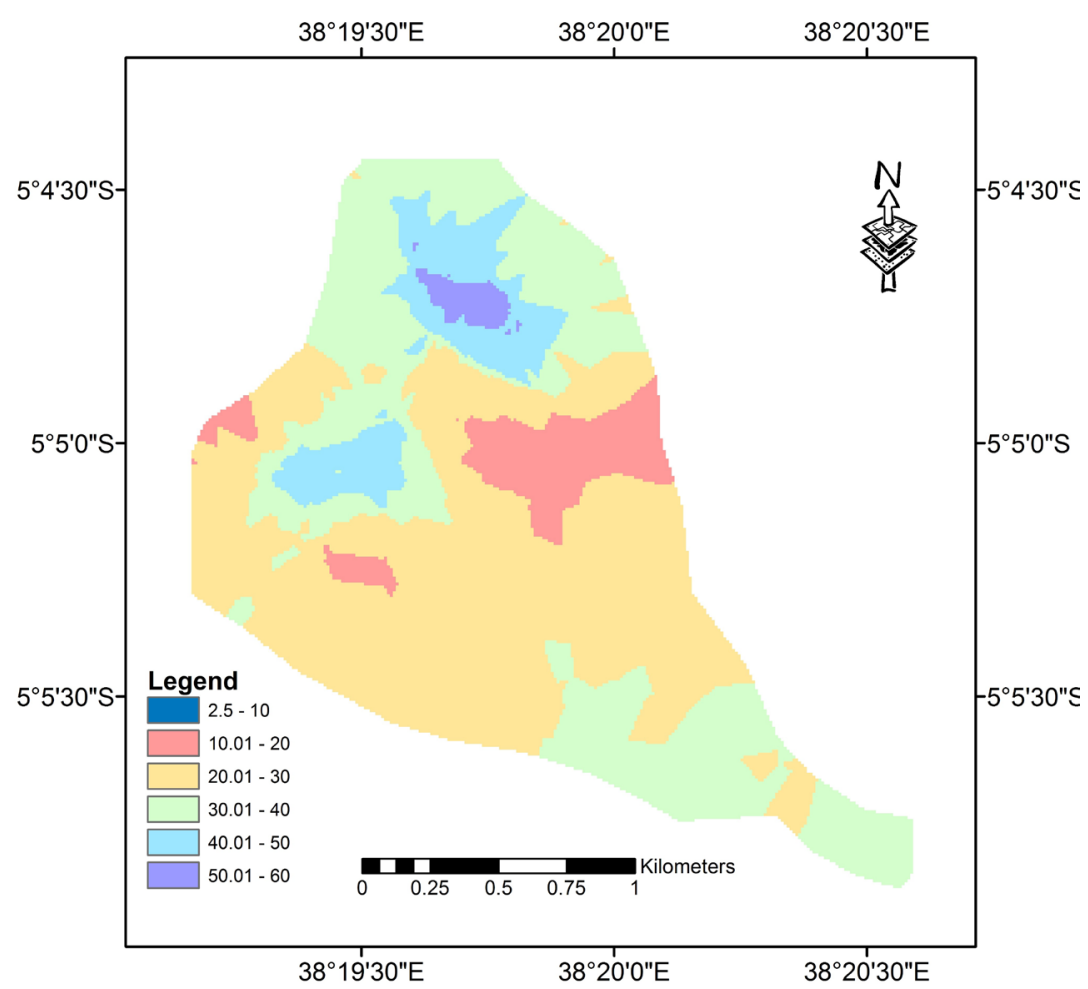

(b)

Figure 6. TDR soil moisture point data distributions. 


\section{$\mathrm{RMSH}$}

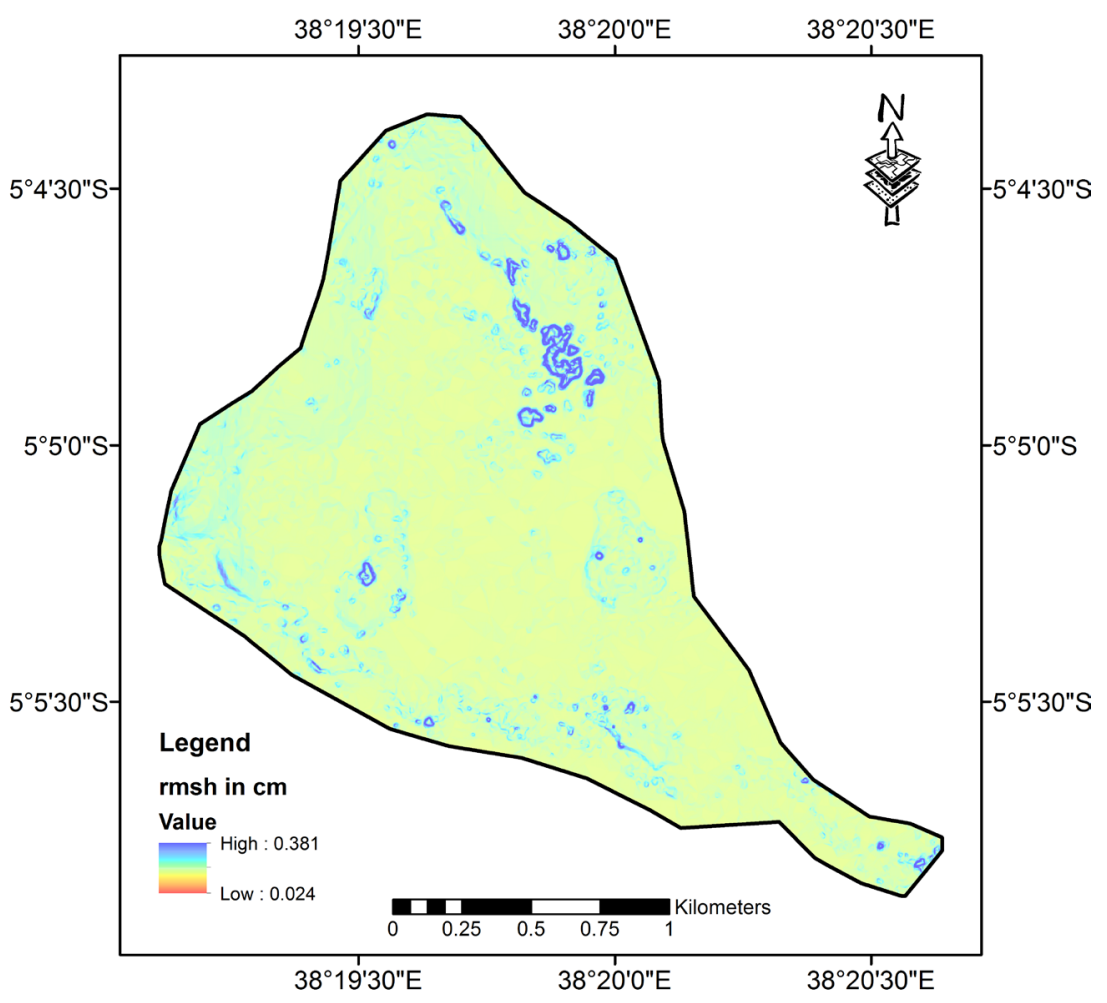

Figure 7. RMSH for the surface roughness parameter (z) as derived from the DSM.

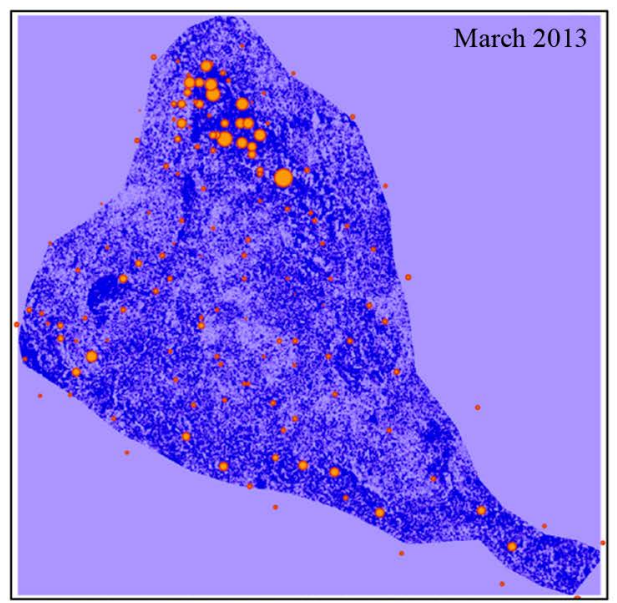

Moisture

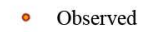

$0-10$

$10-20$

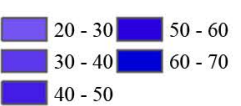

$40-50$

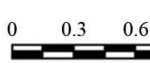

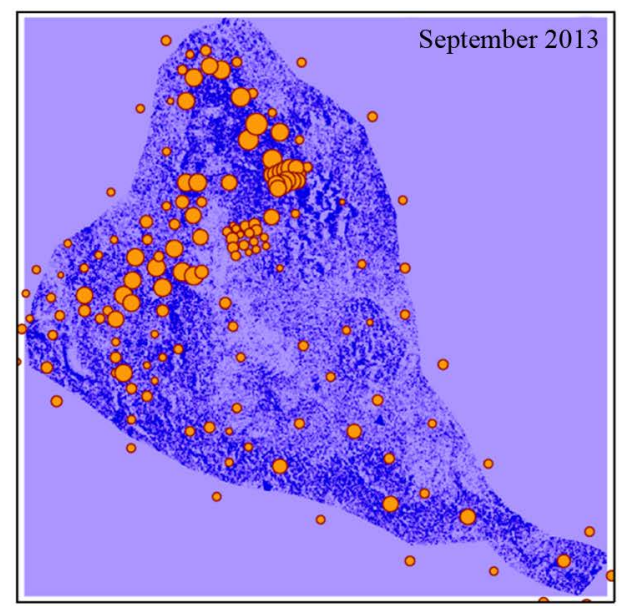

Kilometers
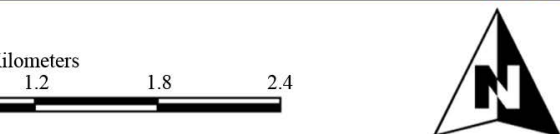

Figure 8. Soil moisture retrieval using Oh model assuming bare ground condition.

September, soil moisture is underestimated due to influence of maturing vegetation [1]. In the presence of vegetation, the soil is sheltered and thus moisture retrieved was less than the actual soil moisture.

In case II, vegetation contribution was considered. While vegetation moisture measurements were not collected, the WCM was used to determine the vegetation contribution by utilizing the RGVI from UAV photographs as a canopy descriptor. The Oh model was then used to retrieve soil moisture from vegetation free backscatter. 
Figure 9 shows the vegetation moisture content and Figure 10 shows soil moisture retrievals where vegetation contribution has been considered. This vegetation moisture content can be related to biomass although not in a linear trend [40].

By considering the presence of vegetation, there is marked improvement in the soil moisture retrievals in both observation periods as shown in Figure 10. While vegetation moisture content was not validated, considering the effects of vegetation improved the estimated soil moisture across the wetland. This is consistent with the observed state since March was much drier compared to September.

There is a correlation between the vegetation moisture and soil moisture to some extent, as vegetated soil is able to retain moisture more than bare ground. Figure 10 shows the comparison of soil moisture between retrieved and observed conditions. As alluded to earlier, there is good correspondence between the retrievals and the observations providing some level of validation of our retrieval approaches. Figure 11 shows the results of running the algorithm on the radar data for the period under study.

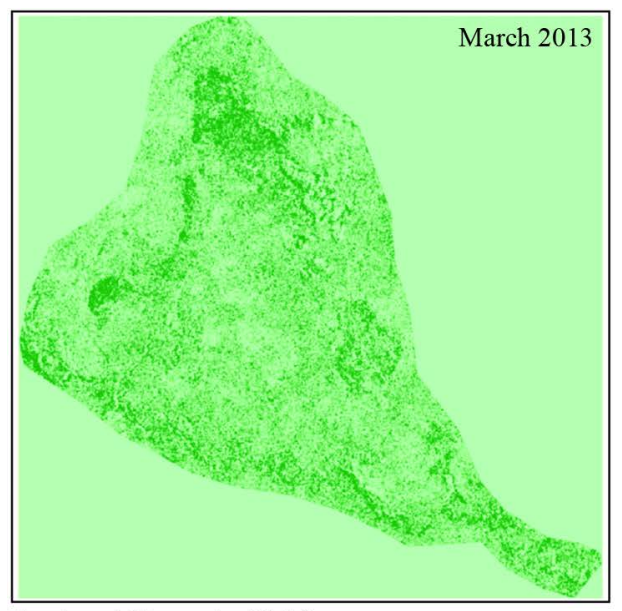

Retrieved Vegetationl Moisture
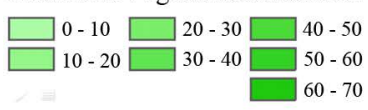
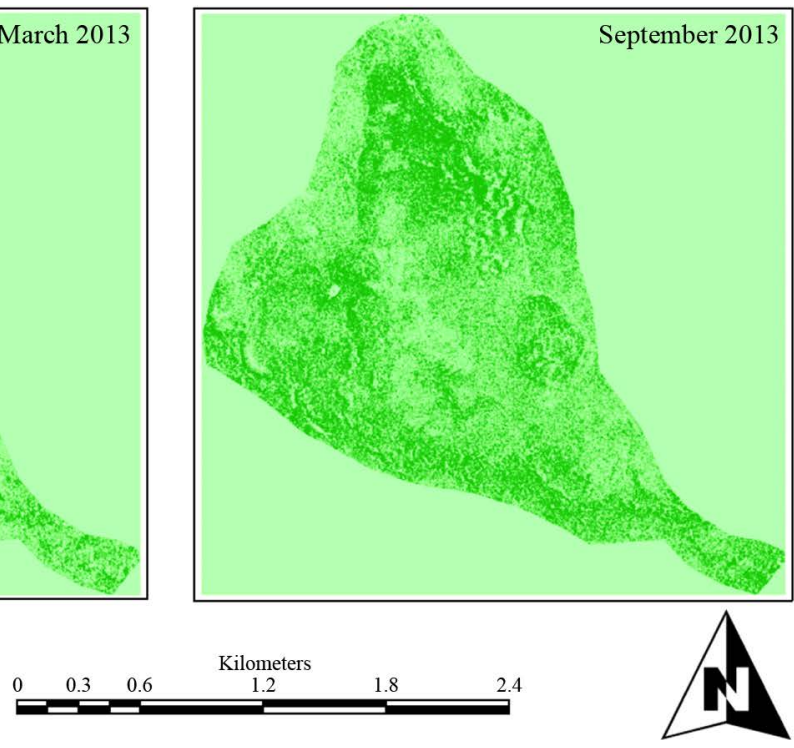

Figure 9. Vegetation moisture retrieval for the period under study.
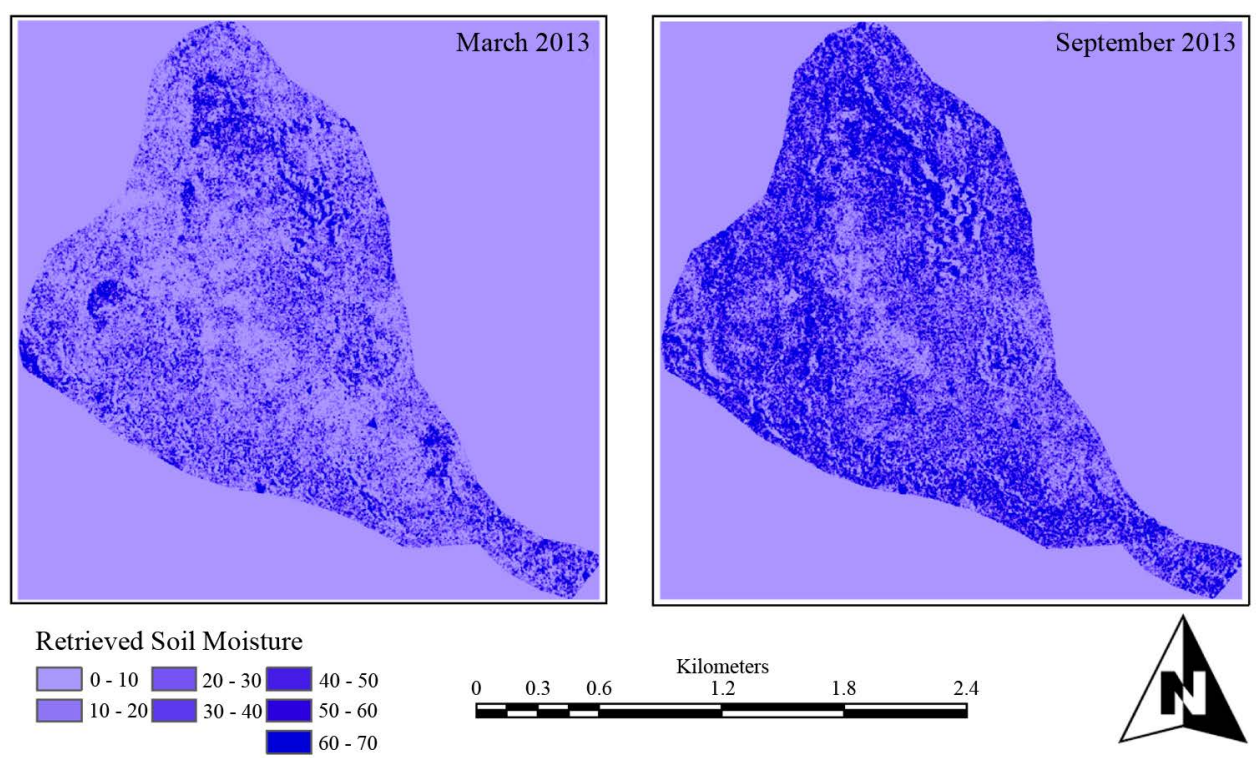

Figure 10. Improved soil moisture retrieval using the Oh model by considering the presence of vegetation cover. 


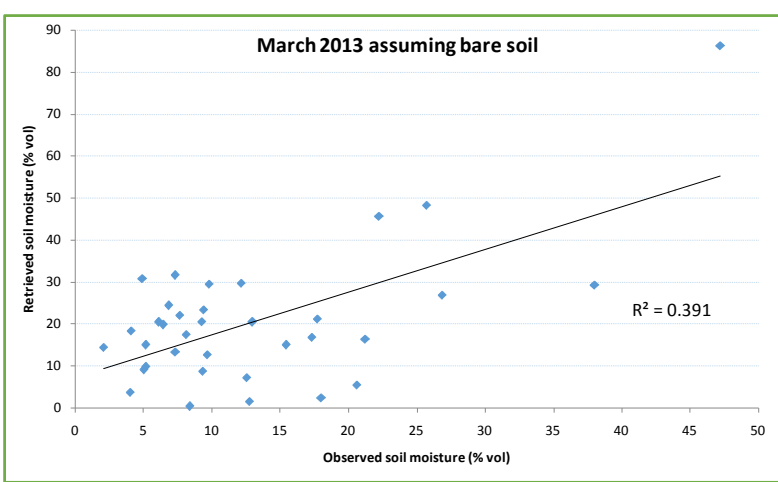

(a)

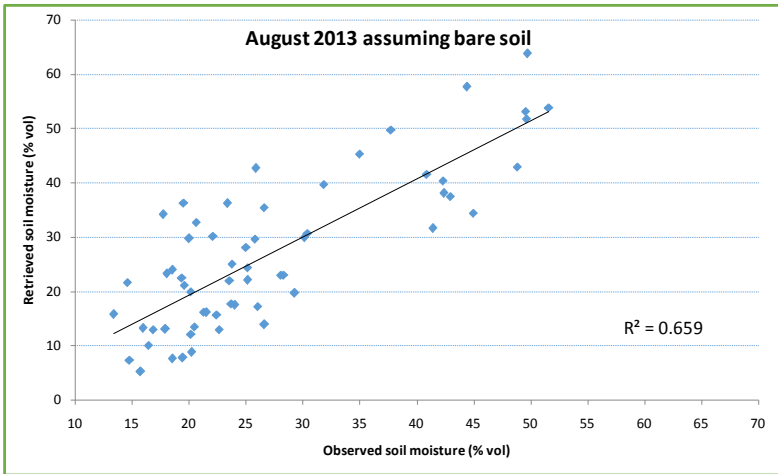

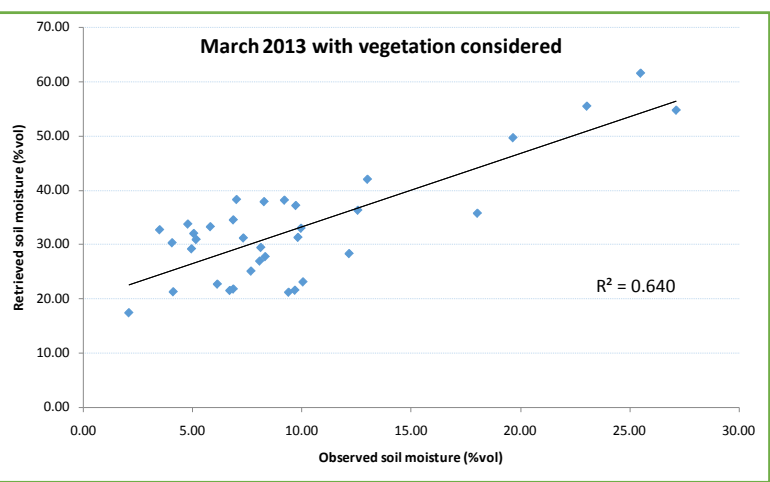

(b)

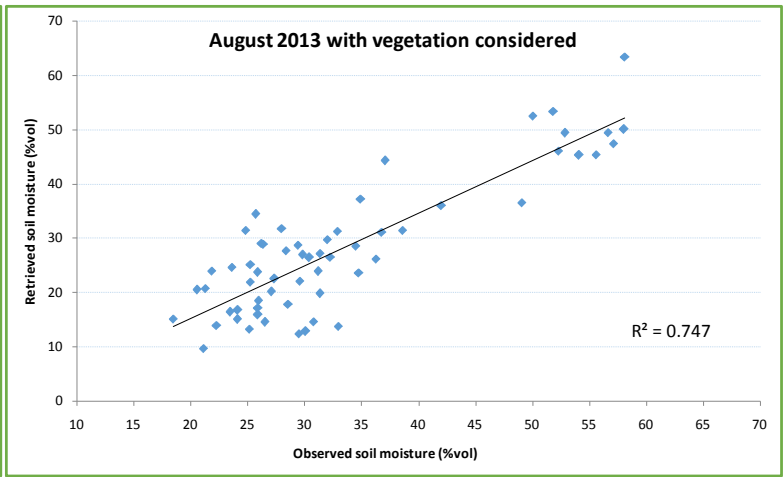

Figure 11. Soil moisture comparison between observed and retrieved for March and August 2013.

\section{Conclusions and Summary}

Field soil moisture measurements were made in March and August 2013. TerraSAR-X data were obtained for March and September 2013. Soil moisture distribution was interpolated from TDR point measurements using kriging functions. Surface roughness conditions were computed using DSM. These conditions were applied in an attempt to retrieve soil moisture conditions from the radar datasets. The soil moisture retrieval algorithm used the Oh's Model.

This study has presented the probability of utilizing a vegetation index calculated from UAV photos taken within the visible part of the spectrum to improve soil moisture retrieval. This is crucial especially in cases where the NIR cameras are not readily available.

A first guess of soil moisture was obtained by considering the retrieval case for bare ground conditions. These retrievals while largely consistent in distribution, overestimated retrievals for dry conditions while underestimating retrievals for wetter conditions. To mitigate this, retrievals considering vegetation cover were done by using the water cloud approximation to model vegetation moisture. The vegetation moisture was determined by utilizing the RGVI obtained from UAV photographs of the area. Negating the effects of vegetation showed marked improvement in the retrieved soil moisture for both dry and wet conditions.

Further research should be carried out to assess other vegetation indices that can be utilized to represent vegetation and vegetation water content in the absence of the NIR band from remotely sensed products.

\section{Acknowledgements}

This research work was funded by Volkswagen Stiftung through the "Agricultural use and vulnerability of Small Wetlands in East Africa (SWEA)" project. The GlobE East African Wetlands Project provided an opportunity to be part of this research through funding the author. The TerraSAR-X images were obtained through a data proposal from the German Aerospace Center (DLR). We acknowledge the contribution of the anonymous reviewers for their useful comments. 


\section{References}

[1] Kuria, D.N., Menz, G., Misana, S., Mwita, E., Thamm, H.-P., Alvarez, M., Mogha, N., Becker, M. and Oyieke, H. (2014) Seasonal Vegetation Changes in the Malinda Wetland Using Bi-Temporal, Multi-Sensor, Very High Resolution Remote Sensing Data Sets. Advances in Remote Sensing, 3, 33-48. http://dx.doi.org/10.4236/ars.2014.31004

[2] Álvarez-Mozos, J., Verhoest, N.E.C., Larrañaga, A., Casalí, J. and González-Audícana, M. (2009) Influence of Surface Roughness Spatial Variability and Temporal Dynamics on the Retrieval of Soil Moisture from SAR Observations. Sensors, 9, 463-489. http://dx.doi.org/10.3390/s90100463

[3] Kornelsen, K.C. and Coulibaly, P. (2013) Advances in Soil Moisture Retrieval from Synthetic Aperture Radar and Hydrological Applications. Journal of Hydrology, 476, 460-489. http://dx.doi.org/10.1016/j.jhydrol.2012.10.044

[4] D’Urso, G. and Minacapilli, M. (2006) A Semi-Empirical Approach for Surface Soil Water Content Estimation from Radar Data without a-Priori Information on Surface Roughness. Journal of Hydrology, 321, 297-310. http://dx.doi.org/10.1016/j.jhydrol.2005.08.013

[5] Rahman, M.M., Moran, M.S., Thoma, D.P., Bryant, R., Holifield Collins, C.D., Jackson, T., Orr, B.J. and Tischler, M. (2008) Mapping Surface Roughness and Soil Moisture Using Multi-Angle Radar Imagery without Ancillary Data. Remote Sensing of Environment, 112, 391-402. http://dx.doi.org/10.1016/j.rse.2006.10.026

[6] Merlin, O., Walker, J., Chehbouni, A. and Kerr, Y. (2008) Towards Deterministic Downscaling of SMOS Soil Moisture Using MODIS Derived Soil Evaporative Efficiency. Remote Sensing of Environment, 112, 3935-3946. http://dx.doi.org/10.1016/j.rse.2008.06.012

[7] Liu, Y.Y., Parinussa, R.M., Dorigo, W.A., De Jeu, R.A.M., Wagner, W., van Dijk, A.I.J.M., McCabe, M.F. and Evans, J.P. (2011) Developing an Improved soil Moisture Dataset by Blending Passive and Active Microwave Satellite-Based Retrievals. Hydrology and Earth System Sciences, 15, 425-436. http://dx.doi.org/10.5194/hess-15-425-2011

[8] Wang, S.G., Li, X., Han, X.J. and Jin, R. (2011) Estimation of Surface Soil Moisture and Roughness from MultiAngular ASAR Imagery in the Watershed Allied Telemetry Experimental Research (WATER). Hydrology and Earth System Sciences, 15, 1415-1426. http://dx.doi.org/10.5194/hess-15-1415-2011

[9] He, B., Xing, M. and Bai, X. (2014) A Synergistic Methodology for Soil Moisture Estimation in an Alpine Prairie Using Radar and Optical Satellite Data. Remote Sensing, 6, 10966-10985. http://dx.doi.org/10.3390/rs61110966

[10] Hajnsek, I., Jagdhuber, T., Schon, H. and Papathanassiou, K.P. (2009) Potential of Estimating Soil Moisture under Vegetation Cover by Means of PolSAR. IEEE Transactions on Geoscience and Remote Sensing, 47, 442-454. http://dx.doi.org/10.1109/TGRS.2008.2009642

[11] Baghdadi, N., Aubert, M. and Zribi, M. (2012) Use of TerraSAR-X Data to Retrieve Soil Moisture over Bare Soil Agricultural Fields. IEEE Geoscience and Remote Sensing Letters, 9, 512-516. http://dx.doi.org/10.1109/LGRS.2011.2173155

[12] Schmitt, A., Leichtle, T., Huber, M. and Roth, A. (2012) On the Use of Dual-Co-Polarized TerraSAR-X Data for Wetland Monitoring. ISPRS-International Archives of the Photogrammetry, Remote Sensing and Spatial Information Sciences, XXXIX-B7, 341-344. http://dx.doi.org/10.5194/isprsarchives-XXXIX-B7-341-2012

[13] Kuria, D., Koike, T., Lu, H., Graf, T. and Tsutsui, H. (2011) A Coupled Land Atmosphere Radiative-Transfer Model (LA-RTM) for Multi-Frequency Passive Microwave Remote Sensing: Development and Application over Wakasa Bay and the Tibetan Plateau. International Journal of Remote Sensing, 32, 1779-1796. http://dx.doi.org/10.1080/01431161003621627

[14] Lievens, H. and Verhoest, N.E.C. (2011) On the Retrieval of Soil Moisture in Wheat Fields from L-Band SAR Based on Water Cloud Modeling, the IEM, and Effective Roughness Parameters. IEEE Geoscience and Remote Sensing Letters, 8, 740-744. http://dx.doi.org/10.1109/LGRS.2011.2106109

[15] Trudel, M., Charbonneau, F. and Leconte, R. (2012) Using RADARSAT-2 Polarimetric and ENVISAT-ASAR Dual-Polarization Data for Estimating Soil Moisture over Agricultural Fields. Canadian Journal of Remote Sensing, 38, 514-527.

[16] Koyama, C.N. (2012) Quantitative Estimation of Surface Soil Moisture in Agricultural Landscapes Using Spaceborne Synthetic Aperture Radar Imaging at Different Frequencies and Polarizations. Universität zu Köln, Inaugural-Dissertation zur Erlangung des Doktorgrades der Mathematisch-Naturwissenschaftlichen Fakultät.

[17] Khabazan, S., Motagh, M. and Hosseini, M. (2013) Evaluation of Radar Backscattering Models IEM, OH, and Dubois Using L and C-Bands SAR Data over Different Vegetation Canopy Covers and Soil Depths. ISPRS-International Archives of the Photogrammetry, Remote Sensing and Spatial Information Sciences, XL-1/W3, 225-230. http://dx.doi.org/10.5194/isprsarchives-XL-1-W3-225-2013

[18] Panciera, R., Tanase, M.A., Lowell, K. and Walker, J.P. (2014) Evaluation of IEM, Dubois, and Oh Radar Backscatter 
Models Using Airborne L-Band SAR. IEEE Transactions on Geoscience and Remote Sensing, 52, 4966-4979. http://dx.doi.org/10.1109/TGRS.2013.2286203

[19] Baghdadi, N. and Zribi, M. (2006) Evaluation of Radar Backscatter Models IEM, OH and Dubois Using Experimental Observations. International Journal of Remote Sensing, 27, 3831-3852. http://dx.doi.org/10.1080/01431160600658123

[20] Oh, Y., Sarabandi, K. and Ulaby, F.T. (1992) An Empirical Model and an Inversion Technique for Radar Scattering from Bare Soil Surfaces. IEEE Transactions on Geoscience and Remote Sensing, 30, 370-381. http://dx.doi.org/10.1109/36.134086

[21] Dubois, P.C., van Zyl, J. and Engman, T. (1995) Measuring Soil Moisture with Imaging Radars. IEEE Transactions on Geoscience and Remote Sensing, 33, 915-926. http://dx.doi.org/10.1109/36.406677

[22] Attema, E.P.W. and Ulaby, F.T. (1978) Vegetation Modeled as a Water Cloud. Radio Science, 13, 357-364. http://dx.doi.org/10.1029/RS013i002p00357

[23] Prakash, R., Singh, D. and Pathak, N.P. (2012) A Fusion Approach to Retrieve Soil Moisture with SAR and Optical Data. IEEE Journal of Selected Topics in Applied Earth Observations and Remote Sensing, 5, 196-206. http://dx.doi.org/10.1109/JSTARS.2011.2169236

[24] Tan, L., Chen, Y., Jia, M., Tong, L., Li, X. and He, L. (2015) Rice Biomass Retrieval from Advanced Synthetic Aperture Radar Image Based on Radar Backscattering Measurement. Journal of Applied Remote Sensing, 9, Article ID: 097091. http://dx.doi.org/10.1117/1.JRS.9.097091

[25] McNairn, H., Shang, J., Jiao, X. and Deschamps, B. (2012) Establishing Crop Productivity Using Radarsat-2. ISPRS - International Archives of the Photogrammetry, Remote Sensing and Spatial Information Sciences, XXXIX-B8, 283-287. http://dx.doi.org/10.5194/isprsarchives-XXXIX-B8-283-2012

[26] Koppe, W., Gnyp, M.L., Hütt, C., Yao, Y., Miao, Y., Chen, X. and Bareth, G. (2013) Rice Monitoring with MultiTemporal and Dual-Polarimetric TerraSAR-X Data. International Journal of Applied Earth Observation and Geoinformation, 21, 568-576. http://dx.doi.org/10.1016/j.jag.2012.07.016

[27] Baghdadi, N., Camus, P., Beaugendre, N., Issa, O.M., Zribi, M., Desprats, J.F., Rajot, J.L., Abdallah, C. and Sannier, C. (2011) Estimating Surface Soil Moisture from TerraSAR-X Data over Two Small Catchments in the Sahelian Part of Western Niger. Remote Sensing, 3, 1266-1283. http://dx.doi.org/10.3390/rs3061266

[28] Baghdadi, N., Boyer, N., Todoroff, P., El Hajj, M. and Bégué, A. (2009) Potential of SAR Sensors TerraSAR-X, ASAR/ENVISAT and PALSAR/ALOS for Monitoring Sugarcane Crops on Reunion Island. Remote Sensing of Environment, 113, 1724-1738. http://dx.doi.org/10.1016/j.rse.2009.04.005

[29] Candiago, S., Remondino, F., De Giglio, M., Dubbini, M. and Gattelli, M. (2015) Evaluating Multispectral Images and Vegetation Indices for Precision Farming Applications from UAV Images. Remote Sensing, 7, 4026-4047. http://dx.doi.org/10.3390/rs70404026

[30] Martínez-Casasnovas, J.A., Ariza-Sentís, M., Maresma, A., Martínez, E. and Lloveras, J. (2015) Vegetation Indices from Unmanned Aerial Vehicles-Mounted Sensors to Monitor the Development of Maize (Zea mays L.) under Different N Rates. In: Stafford, J.V., Ed., Precision Agriculture '15, Wageningen Academic Publishers, Wageningen, 119-126. http://dx.doi.org/10.3920/978-90-8686-814-8_14

[31] Mutua, F. and Kuria, D. (2012) A Comparison of Spatial Rainfall Estimation Techniques: A Case Study of Nyando River Basin Kenya. Journal of Agricultural Science and Technology, 14, 149-165.

[32] AirBus Defence and Space (2014) Radiometric Calibration of TerraSAR-X Data.

[33] Jester, W. and Klik, A. (2005) Soil Surface Roughness Measurement-Methods, Applicability, and Surface Representation. CATENA, 64, 174-192. http://dx.doi.org/10.1016/j.catena.2005.08.005

[34] Verhoest, N.E., Lievens, H., Wagner, W., Álvarez-Mozos, J., Moran, M.S. and Mattia, F. (2008) On the Soil Roughness Parameterization Problem in Soil Moisture Retrieval of Bare Surfaces from Synthetic Aperture Radar. Sensors, 8, 4213-4248. http://dx.doi.org/10.3390/s8074213

[35] Marzahn, P. (2012) Multi-Dimensional Characterization of Soil Surface Roughness for Microwave Remote Sensing Applications. Dissertation, Fakultat fur Geowissenschaften der Ludwig-Maximilians-Universitat Munchen, Hamburg.

[36] Marzahn, P., Rieke-Zapp, D. and Ludwig, R. (2012) Assessment of Soil Surface Roughness Statistics for Microwave Remote Sensing Applications Using a Simple Photogrammetric Acquisition System. ISPRS Journal of Photogrammetry and Remote Sensing, 72, 80-89. http://dx.doi.org/10.1016/j.isprsjprs.2012.06.005

[37] Karam, M.A., Fung, A.K., Lang, R.H. and Chauhan, N.S. (1992) A Microwave Scattering Model for Layered Vegetation. IEEE Transactions on Geoscience and Remote Sensing, 30, 767-784. http://dx.doi.org/10.1109/36.158872

[38] Ewe, H.T. and Chuah, H.T. (2000) A Study of Fresenel Scattered Field for Non-Spherical Discrete Scatterers. Progress in Electromagnetic Research, 25, 189-222. http://dx.doi.org/10.2528/PIER99060701 
[39] Bindlish, R. and Barros, A.P. (2001) Parameterization of Vegetation Backscatter in Radar-Based, Soil Moisture Estimation. Remote Sensing of Environment, 76, 130-137. http://dx.doi.org/10.1016/S0034-4257(00)00200-5

[40] Englhart, S., Keuck, V. and Siegert, F. (2011) Aboveground Biomass Retrieval in Tropical Forests-The Potential of Combined X- and L-Band SAR Data Use. Remote Sensing of Environment, 115, 1260-1271.

http://dx.doi.org/10.1016/j.rse.2011.01.008 